\title{
The Role of Lipid Peroxidation in Storage Disorders of Fresh Fruits and Vegetables
}

\author{
R.L. Shewfelt ${ }^{1}$ and B.A. del Rosario \\ University of Georgia, Department of Food Science and Technology, Athens, GA 30602
}

Reduction of postharvest losses of plant products has been described as the second harvest (Bourne, 1977). These losses are particularly distressing, as all of the production and harvesting inputs have been made for food that will never provide nourishment. The losses may be physiological consequences of a response to biotic or abiotic stress. This article focuses on physiological responses of harvested products to stress (primarily physical) that result in loss of quality or acceptability. It argues that lipid peroxidation, generally relegated to the status of a secondary effect of a primary event responsible for the degradation process, could actually be a critical, controllable event common to the mechanism of many of these storage disorders.

\section{STORAGE DISORDERS}

A storage disorder of a fresh fruit or vegetable is any adverse response that results in a detectable loss in quality. Microbial decay

\footnotetext{
Received for publication 26 May 1999. Accepted for publication 10 Aug. 1999. The cost of publishing this paper was defrayed in part by the payment of page charges. Under postal regulations, this paper therefore must be hereby marked advertisement solely to indicate this fact.

${ }^{1}$ To whom reprint requests should be addressed. Phone: 706-542-5136; fax:

706-542-1050; e-mail: shewfelt@arches.uga.edu
}

due to the presence and active growth of plant pathogens is a prevalent form of storage disorder. Another form is response to stress induced by the storage environment (low temperature, high temperature, low relative humidity, high $\mathrm{CO}_{2}$, low $\mathrm{O}_{2}$, or excess light). Much of the stress induced by storage environment is the result of attempts to prevent or retard microbial decay and the ultimate storage disordersenescence.

Cellular membranes are generally considered the primary locus of many storage disorders, but the mechanism remains obscure (Marangoni et al., 1996). The phase transition hypothesis, initially advanced by Lyons (1973) in connection with chilling injury, has largely been discredited. The idea that physical properties of membranes are of critical importance in cell function and that they are a plausible target for deterioration during cellular response to stress is still widely held (as reviewed by Shewfelt, 1992). A more recent incarnation of the phase transition hypothesis proposes that there is a primary event that is the ultimate cause of membrane disorder, and suggests that any solution requires the identification and treatment of the primary event rather than of secondary effects (Raison and Orr, 1990). Potential candidates for the primary event include:

- a biophysical change in membranes,

- alteration of conformation of critical enzymes,

- modification of the cytoskeleton, and

- major changes in calcium balance. 
The inability to clearly establish a primary event, the growing interest in finding molecular solutions to every physiological problem, and the lack of ready application of current molecular techniques to the study of lipids has limited pursuit of the role of membranes in the etiology of storage disorders.

Medical interest in antioxidants in the prevention of human diseases (cancer, diabetes, heart disease, etc.) and the presence of such antioxidants in fresh fruits and vegetables has rekindled interest in lipid peroxidation in plant tissue, but the linkages among lipid peroxidation, membrane deterioration, and plant disorders have not yet been convincingly demonstrated. The most plausible explanation for the role of antioxidants in the prevention of human or plant disease is the prevention of propagation of peroxidation in membrane lipids. Complete elimination of initiation reactions of lipid peroxidation in living tissue that encompasses such oxidative processes as respiration, photosynthesis, and oxidative phosphorylation is impractical. In a postharvest environment such oxidative processes can be eliminated by enzyme-inactivation processes, such as heating, freezing, and/or drying. Unfortunately, such food processes have adverse effects on flavor, texture, color, and nutritive value in the transition from a fresh to a processed product. Antioxidants protect membrane lipids of fresh fruits and vegetables from peroxidative degradation, thus maintaining physical integrity and providing a healthy environment for membranebound enzymes to function in. Thus, peroxidation is a cellular process that could be controlled by manipulation of antioxidant concentrations at critical locations in the cell to prevent or retard the development of storage disorders. Chemical analysis of gross effects on antioxidant status and peroxidation at the tissue or whole cell levels is unlikely to provide useful information in control of membrane peroxidation. Rather, successful investigation will require an understanding of effects on specific membranes within the cell in the context of cellular physiology.

\section{LIPID PEROXIDATION OF PLANT MEMBRANES}

Lipid peroxidation can be viewed as a consequence of life. Peroxidative products increase during plant senescence (Meir et al., 1992; Pauls and Thompson, 1984; Pogson and Morris, 1997), in response to temperature extremes (Butow et al., 1998; Dat et al., 1998; Prasad, 1996; Walker and McKersie, 1993; Wismer et al., 1998) and in hypersensitive response to microbial attack (Beckman and Ingram, 1994; Legendre et al., 1993). Whether the accumulation of these products is a cause or an effect of deterioration is not clear (Shewfelt and Purvis, 1995). Both nonenzymic and enzymic defense compounds exist to prevent peroxidation or limit adverse effects. Antioxidants such as $\beta$-carotene, lycopene, and $\alpha$-tocopherol, as well as reducing agents such as ascorbic acid and glutathione, help limit peroxidative damage. Enzymes important in protecting membranes from lipid peroxidation include catalase, peroxidase, and superoxide dismutase.

Similar peroxidative and antioxidative processes occur in harvested tissue. Many postharvest storage strategies seek to slow the development of senescence by slowing respiration. Storage at low temperatures above the freezing point can result in chilling injury in susceptible plant species. Increased lipid peroxidation has been observed in the development of chilling injury in many crops, such as cucumber (Cucumis sativus L.) (Hariyadi and Parkin, 1993) and zucchini squash (Curcurbita sp.) (Wang and Sass, 1994). Lipid peroxidation has also been associated with the development of UV damage in spinach (Spinacia oleracea L.) leaves (DeLong and Steffan, 1997) and superficial scald in apples (Malus $\times$ domestica Borkh.) (Du and Bramlage, 1995; Rao et al., 1998). Senescence and lipid peroxidation have been linked in broccoli (Brassica oleracea L. Botrytis Group) buds (Zhuang et al., 1995) and cabbage (Brassica oleracea L. Capitata Group) leaves (Cheour et al., 1992). Although most of the research on heat shock has focused on the production of polypeptides known as heat-shock proteins, lipid peroxidation has been observed in pea (Pisum sativum L.) chloroplasts subjected to high temperatures (Basra et al., 1997; Kurganova et al., 1997). Association of these disorders with peroxidation does not necessarily imply a cause-effect relationship, but there has been little attempt to understand or explain any potential relationship between the two. Rather, much of the research has been directed at finding a simple point of intervention, preferably by identifying a target enzyme amenable to gene manipulation.

The wide range of symptoms evidenced in different types of plant tissue for any single type of disorder, such as chilling injury, let alone for cellular response to a wide range of biotic and abiotic stresses, indicates that a single all-encompassing mechanism is highly unlikely. A more likely possibility is a point of commonality within a wide range of disorders. In a model proposed by Shewfelt and Erickson (1991) and amplified elsewhere (Erickson et al., 1996; Purvis and Shewfelt, 1993; Shewfelt, 1992; Shewfelt and Purvis, 1995), lipid peroxidation of specific susceptible membranes was described as the effect of a specific response of a plant cell to external stress that could serve as a point of commonality (Fig. 1). Deterioration of the lipids would lead to loss of membrane integrity, physical structure, and membrane fluidity that would in turn affect proper function of proteins either by direct attack on the proteins by reactive oxygen species or loss of activity due to an unfavorable lipid environment. Failure of a critical enzyme within a specific membrane would lead to metabolic imbalances within the cell manifested at the tissue level as visible symptoms of a disorder. The symptoms would be dependent on the membrane
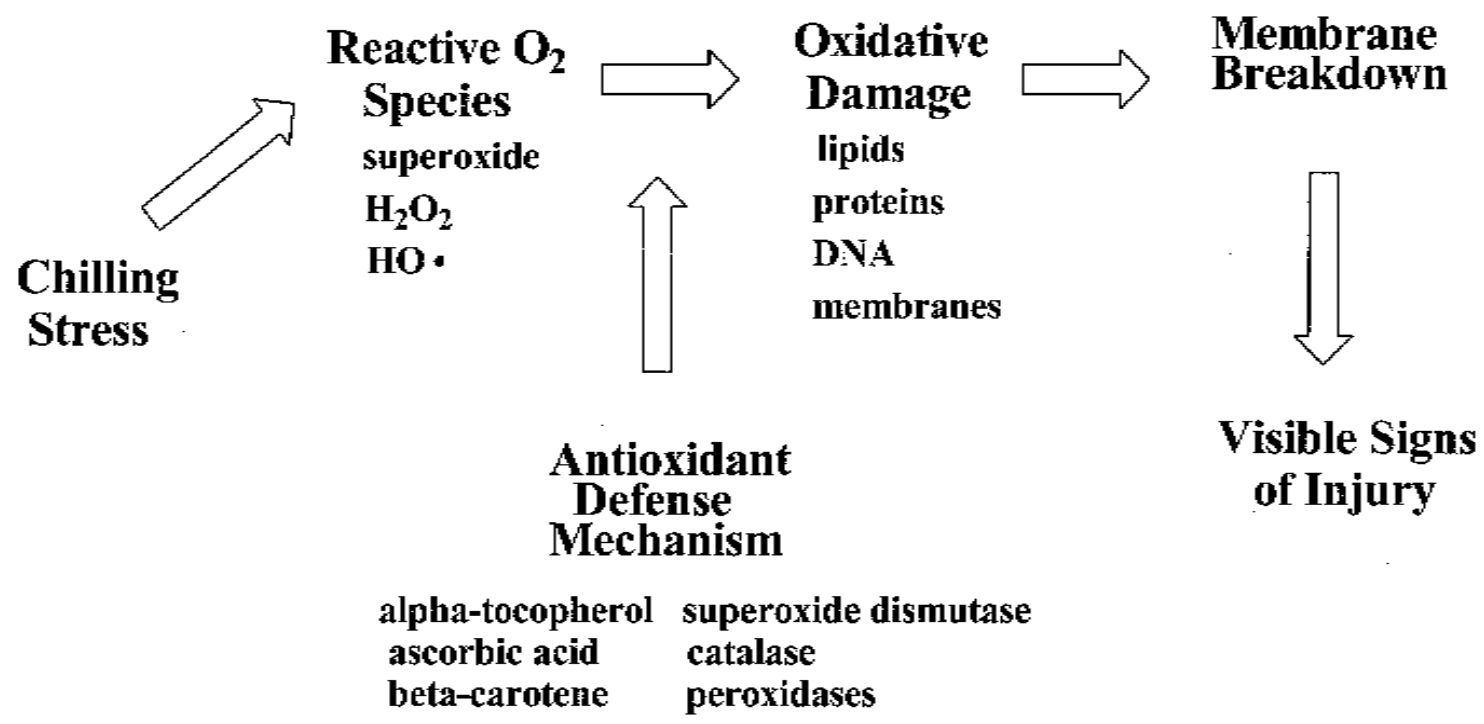

Fig. 1. Schematic of conceptual model proposed to explain the role of lipid peroxidation in chilling injury and other membrane disorders of plant tissue. 
affected, its role in cell physiology, and the type of tissue affected. If lipid peroxidation is truly a point of commonality for many plant tissue disorders, it could also be a point of commonality for controlling these disorders and minimizing the associated economic losses.

Peroxidation of membranes can proceed through either biochemical (enzymic) or chemical (nonenzymic) processes. Enzymes are attractive targets for genetic manipulation, and enzymic systems exist in the cell that both promote and inhibit lipid peroxidation. Primary enzymic sources of reactive oxygen species in plant cells include photosystem II (Tijskens et al., 1994) and electron transport (Purvis and Shewfelt, 1993). Expression of antioxidant enzymes increases at the early stages of senescence in chrysanthemum (Dendranthema $\times$ grandiflora Kitam.) petals (Bartoli et al., 1995), suggesting the triggering of a defense response to oxidative attack. Lipoxygenases can attack membrane lipids, usually preferring free fatty acids and proceeding through nonradical processes (Gardner, 1995). An enzyme pathway described by Paliyath and Thompson (1987) forms the free fatty acids within the membrane. Superoxide dismutase, catalase, peroxidase, glutathione reductase, and ascorbate peroxidase are enzymes that intervene in the defense against reactive oxygen species, while the alternative pathway has also been proposed as a means of reducing production of these reactive compounds (Purvis and Shewfelt, 1993). Enzymic repair systems can remove peroxidized fatty acids from the membrane, thus reducing opportunities for propagation.

Numerous studies report changes in activities of specific enzymes during the development of ripening (Rogiers et al., 1998), senescence (Bartoli et al., 1995; Lacan and Baccou, 1998; Sung and Chiu, 1995; Zhuang et al., 1995), or storage disorders (Kurganova et al., 1997; Pinhero et al., 1997; Prasad, 1997; Rao et al., 1998; Wang, 1996). Genetic manipulation (Allen et al., 1997) or chemical induction of these enzymes provide convenient ways of studying stress response, but the results have been inconsistent and sometimes unexpected. Multiple antioxidant enzymes have been induced as part of a protective response to salt tolerance in cotton (Gossypium hirsutum L.) (Gossett et al., 1994), paraquat resistance (Ye and Gressel, 1994), and drought resistance in maize (Zea mays L.) (Li and van Staden, 1998). In less definitive results, decreased lipoxygenase activity in soybean (Glycine max L.) seeds (Wang et al., 1990), and jasmonic acidinduced lipoxygenase activity in wheat (Triticum aestivum L.) leaf segments (Rafi et al., 1996) accelerated senescence. Increased activity of superoxide dismutase did not protect tobacco (Nicotiana sp.), tomato (Lycopersicon esculentum L.) (Tepperman and Dunsmuir, 1990), or cotton plants (Payton et al., 1997) from increased production of superoxide, while increases in the enzyme increased chilling tolerance in maize seedlings (Polodorios and Scandalios, 1997; Zhang et al., 1995) and freezing tolerance in alfalfa (Medicago sativa L.) (McKersie et al., 1993). Differences in response appear to be related to the isozyme of the enzyme modified, the organellar location, and accompanying activities of catalase. Decreased catalase activity was associated with an increase in thermotolerance of mustard (Brassica sp.) seedlings (Dat et al., 1998). Acclimation of maize seedlings increased both levels of catalase and glutathione reductase and tolerance to chilling stress (Prasad, 1996). Tobacco seedlings transformed to overexpress glutathione peroxidase and glutathione transferase were more resistant to chilling and salt stress (Roxas et al., 1997). Elevated levels of ascorbate peroxidase activity were associated with chilling tolerance in maize but glutathione reductase activity was not affected (Hull et al., 1997). These results suggest that study of lipid peroxidation, defense mechanisms, and their relationship to stress response must not be confined to the tissue and cellular levels but must proceed to a study of organelles and their membranes.

In a quest for biochemical explanations, strictly chemical (nonenzymic) interactions that also occur within plant cells have frequently been overlooked. Reactive oxygen species attack the nearest susceptible molecule based on chemical kinetics (Buettner, 1993). These species can be generated within membranes in the presence of minerals, and kinetics favor reaction with polyunsaturated lipids. Just as free-radical scavengers, singlet-oxygen quenchers, and chain-reaction breakers protect polyunsaturated lipids from reactive oxygen species, lipids are preferentially oxidized to protect proteins and nucleic acids.
Static depictions of membrane bilayers tend to obscure the importance of biophysical properties of membrane lipids and proteins (Leshem, 1992; Silver, 1985). The concentration of polyunsaturated fatty acids in plant membranes, their orientation in membrane phospholipids, and their rapid translational and rotational mobility favor propagation of lipid peroxyl free-radicals. Each point of initiation can result in the formation of 10 to 100 free-radicals prior to termination. $\alpha$-Tocopherol is a very effective breaker of these propagation chain reactions and can be regenerated through the reducing equivalents provided by ascorbic acid. Disappearance of $\alpha$-tocopherol within a specific membrane is the first sign of oxidative degradation of that membrane. As described above, repair mechanisms remove lipid hydroperoxides. While the magnitude of oxidation-reduction reactions occurring in the cell preclude control of the initiation of lipid peroxidation in membranes, control of propagation within membranes appears to be more achievable and more promising (Shewfelt and Erickson, 1991).

While a role for lipid peroxidation as a mediating factor in plant stress response provides a potential common linkage in mechanisms for various symptoms resulting from response to a wide range of biotic and abiotic stresses (Shewfelt and Purvis, 1995), it is still too early to anoint peroxidation as a universal explanation (Marangoni et al., 1996). While some studies have been able to directly link an increase in lipid peroxidation in whole tissue to chilling injury in maize seedlings (Prasad, 1996), bean (Phaseolus vulgaris L.) plants (Zhang et al., 1994), and soybean seeds (Roskruge and Smith, 1997) as well as senescence of soybean seeds (Sung, 1996) and chrysanthemum petals (Bartoli et al., 1995), the evidence is mixed (as reviewed by Shewfelt and Purvis, 1995). One study was able to isolate oxidized proteins as well as oxidized lipids (Prasad, 1996). Few studies have actually examined the effect of peroxidation on specific subcellular membrane fractions, with peroxidation of thylakoids implicated in chilling injury of cucumber seedlings (Hariyadi and Parkin, 1993) but not in loss of photosynthetic function in response of spinach leaves to ultraviolet light (DeLong and Steffen, 1997). Deterioration of the plasma membrane was more pronounced in chilling-resistant bell pepper (Capsicum annuum L.) fruits than in their sensitive counterparts, leading to reduced $\mathrm{H}^{+}$ATPase attributed to increased oxidative stress (Lurie et al., 1994b).

In vitro studies of specific membrane fractions have tested specific aspects of the proposed model. A microsomal fraction from bell pepper fruits exhibited different sensitivities to different challenging systems (Cowart et al., 1995), suggesting that susceptibility of a specific membrane to peroxidation depends on the source of initiation and the specific antioxidant defenses associated with the membrane. Microsomes from cauliflower (Brassica oleracea L. Botrytis Group) florets were found to be more susceptible to peroxidative challenge than those from cowpea [Vigna unguiculata (L.) Walp.] seeds, with the presence of free fatty acids having no effect on susceptibility of the membranes from either tissue (Shewfelt et al., 1994). Mitochondrial and microsomal membranes isolated from bell pepper fruit exhibited different levels of susceptibility to peroxidative challenge (Erickson et al., 1996). That study clearly demonstrated that $\alpha$-tocopherol degradation within a membrane preceded lipid peroxidation, which in turn preceded loss of enzyme function. These results emphasize the importance of understanding the localized response within the cell. Mitochondria are an important source of superoxide in chilling-sensitive bell pepper fruit (Purvis et al., 1995) while the alternative oxidase can limit superoxide production (Purvis, 1997), thus conferring protection to low-temperature exposure.

\section{IMPLICATIONS FOR POSTHARVEST RESEARCH}

Science works best when basic principles can be translated into practical technological solutions. Current technological approaches to minimizing storage disorders in fresh fruits and vegetables tend to focus on manipulation of storage conditions because there is no clear understanding of biochemical control of senescence, chilling injury, and other associated disorders. Response to one type of stress tends to ameliorate response to other types of stress. If cellular membranes do indeed provide a link between storage disorders, study of lipid 
peroxidation provides a potential linkage of these disorders and a means of explaining interrelatedness.

The lack of a linkage between the physiology and technology of postharvest storage disorders may be the result of the lack of a credible theoretical base. The phase transition hypothesis and its incarnations are of little use until a "primary event" can be established.

Genetic manipulation of plant tissue requires targets, preferably enzymes that can be directly linked to cause and effect. If, as we propose, the disorders are primarily chemical consequences of necessary biochemical processes in the cell, then prevention requires intervention at common points of secondary response. Also, if membrane-lipid peroxidation is a point of commonality in a mechanism of many storage disorders, then it could be caused by a number of different stresses and manifest itself in a number of different external symptoms. The simplicity of a common point in the mechanism is obscured, however, by the complexity of membrane response as affected by composition of lipids and antioxidants, function of key enzymes, and their sensitivity to the physical environment of the membrane. The prevalence of lipid peroxidation in membranes during the development of storage disorders demands a rigorous pursuit of its role in the cause and its potential for prevention.

Amelioration of one stress response by another has been observed, but the physiological mechanism is not clear (Lurie et al., 1994a). Conditioning involves a sublethal dose of a stress, to ameliorate response at higher levels of the same stress as has been demonstrated for chilling of grapefruit (Citrus $\times$ paradisi Macfady.) (McDonald et al., 1993) and zucchini squash (Wang, 1995). Chilling injury is decreased by modified atmospheres (Pesis et al., 1994), cutting during fresh-cut operations (O'Connor-Shaw et al., 1994), and high temperatures (McDonald et al., 1996; Sabehat et al., 1996, 1998). As described above, lipid peroxidation of membranes has been observed in each of these disorders. Elicitation of antioxidants and defense or repair systems in response to an initial stress could limit the peroxidation normally elicited in unconditioned tissue or in response to a subsequent stress. Necrotic regions are observed in the epidermis of some plant tissues during hypersensitive response and chilling injury. A similar second-messenger response from stressed tissue is probably responsible for limiting necrosis to selected cells while neighboring cells remain healthy. Glutathione and hydrogen peroxide have been suggested as signaling molecules in response to biotic and abiotic stresses (Foyer et al., 1997). If peroxidation is the mediating response between stress-to-stress interaction, application of sublethal and asymptomatic levels of stress to elicit protection in the cell could provide a relatively simple and effective alternative to conditioning.

Empirical studies on optimizing storage conditions have been remarkably effective at extending shelf life of fresh fruits and vegetables while minimizing storage disorders. Major breakthroughs in refrigeration or storage technology that will significantly improve quality or extend shelf life of intact items beyond current expectations are hard to imagine. Fresh-cut products have presented new problems that are primarily attributed to poor temperature control during distribution. Genetic manipulation has not yet proved effective in successfully modifying complex processes like senescence and chilling injury. Future advances in the prevention of storage disorders will probably stem from advances in a basic understanding of cellular metabolism. Lipid peroxidation of plant membranes is a natural consequence of metabolic processes and may be a mediator of critical events during postharvest storage. It represents a potentially critical means of preventing or controlling plant storage disorders.

\section{Literature Cited}

Allen, R.D., R.P. Webb, and S.A. Schake. 1997. Use of transgenic plants to study antioxidant defenses. Free Radical Biol. Med. 23:473-479.

Bartoli, C.G., M. Simontacchi, J.J. Guiamet, E. Montaldi, and S. Puntarulo. 1995. Antioxidant enzymes and lipid peroxidation during aging of Chrysanthemum ×morifolium Ramat. petals. Plant Sci. 104:161-168.

Basra, R.K., A.S. Basra, C.P. Malik, and I.S. Grover. 1997. Are polyamines involved in the heat-shock protection of mung bean seedlings? Bot. Bul. Acad. Sinica 38:165-169.

Beckman, K.B. and D.S. Ingram. 1994. The inhibition of the hypersensitive response of potato-tuber tissues by cytokinins-Similarities between se- nescence and plant defense responses. Physiol. Mol. Plant Pathol. 45:229_ 246.

Bourne, M.C. 1977. Postharvest food losses-The neglected dimension in increasing the world food supply. Cornell Inst. Agr. Mimeo 53. New York State College Agr. Life Sci., Cornell Univ., Ithaca.

Buettner, G.R. 1993. The pecking order of free radicals and antioxidants: Lipid peroxidation, $\alpha$-tocopherol, and ascorbate. Arch. Biochem. Biophys. 300:535-543.

Butow, B., D. Wyne, A. Sukenik, O. Hadas, and E. Tel-Or. 1998. The synergistic effect of carbon concentration and high temperature on lipid peroxidation in Peridinium gatunense. J. Plankton Res. 20:355-369.

Cheour, F., J. Arul, J. Makhlouf, and C. Willemot. 1992. Delay of membrane lipid degradation by calcium treatment during cabbage leaf senescence. Plant Physiol. 100:1656-1660.

Cowart, D.M., M.C. Erickson, and R.L. Shewfelt. 1995. Susceptibility of microsomal membranes from bell pepper fruit to peroxidative challenge at different temperatures. J. Plant Physiol. 146:639-644.

Dat, J.F., H. Lopez-Delgado, C.H. Foyer, and I.M. Scott. 1998. Parallel changes in $\mathrm{H}_{2} \mathrm{O}_{2}$ and catalase during thermotolerance induced by salicylic acid or heat acclimation in mustard seedlings. Plant Physiol. 116:1351-1357.

DeLong, J.M. and K.L. Steffen. 1997. Photosynthetic function, lipid peroxidation, and alpha-tocopherol content in spinach leaves during exposure to UV-B radiation. Can. J. Plant Sci. 77:453-459.

$\mathrm{Du}, \mathrm{Z}$. and W.J. Bramlage. 1995. Peroxidative activity of apple peel in relation to development of poststorage disorders. HortScience 30:205-209.

Erickson, M.C., R.L. Shewfelt, B.A. del Rosario, G-D. Wang, and A.C. Purvis. 1996. Localized antioxidant degradation in relation to promotion of lipid oxidation, p. 146-158. In: T.C. Lee and H.J. Kim (eds.). Chemical markers for processed and stored foods. Amer. Chem. Soc., Washington, D.C.

Foyer, C.H., H. Lopez-Delgado, J.F. Dat, and I.M. Scott. 1997. Hydrogenperoxide and glutathione-associated mechanisms of acclimatory stress tolerance and signaling. Physiol. Plant. 100:241-254.

Gardner, H.W. 1995. Biological roles and biochemistry of the lipoxygenase pathway. HortScience 30:197-205.

Gossett, D.R., E.P. Millhollon, M.C.Lucas, S.W. Banks, and M. Marney. 1994. The effects of $\mathrm{NaCl}$ on antioxidant enzyme-activities in callus-tissue of salt-tolerant and salt-sensitive cotton cultivars (Gossypium hirsutum L.). Plant Cell Rpt. 13:498-503.

Hariyadi, P. and K.L. Parkin. 1993. Chilling-induced oxidative stress in cucumber (Cucumis sativus L. cv. Calypso) seedlings. J. Plant Physiol. 141:733-738.

Hull, M.R., S.P. Long, and L.S. Jahnke. 1997. Instantaneous and developmental effects of low temperature on the catalytic properties of antioxidant enzymes in two Zea species. Austral. J. Plant Physiol. 24:337-343.

Kurganova, L.N., A.P. Veselov, T.A. Goncharova, and T.V. Sinitsyna. 1997. Lipid peroxidation and antioxidant systems of protection against heat shock in pea (Pisum sativum L.) chloroplasts. Fiziol. Rast. 44:725-730.

Lacan, D. and J.C. Baccou. 1998. High levels of antioxidant enzymes correlate with delayed senescence in nonnetted muskmelon fruits. Planta 204:377382.

Legendre, L., S. Reuter, P.F. Heinstein, and P.S. Low. 1993. Characterization of the oligogalacturonide-induced oxidative burst in cultured soybean (Glycine max) cells. Plant Physiol. 101:1355-1362.

Leshem, Y.Y. 1992. The plant membrane: A biophysical approach. Kluwer, Dordrecht.

Li, L. and J. van Staden. 1998. Effects of plant growth regulators on the antioxidant system in callus of two maize cultivars subjected to water stress. Plant Growth Regulat. 24:55-66.

Lurie, S., J.D. Klein, and E. Fallik. 1994a. Cross protection of one stress by another: strategies in postharvest fruit storage. NATO ASI Ser. H, Cell Biol. 86:201-212.

Lurie, S., R. Ronen, Z. Lipsker, and B. Aloni. 1994b. Effects of paclobutrazol and chilling temperatures on lipids, antioxidants and ATPase activity of plasma-membrane isolated from green bell pepper fruits. Physiol. Plant. 91:593-598.

Lyons, J.M. 1973. Chilling injury in plants. Annu. Rev. Plant Physiol. 24:445466.

Marangoni, A.G., T. Palma, and D.W. Stanley. 1996. Membrane effects in postharvest physiology. Postharvest Biol. Technol. 7:193-217.

McDonald, R.E., T.G. McCollum, and E.A. Baldwin. 1996. Prestorage heat treatments influence free sterols and flavor volatiles of tomatoes stored at chilling temperatures. J. Amer. Soc. Hort. Sci. 121:531-536.

McDonald, R.E., T.G. McCollum, and H.E. Nordby. 1993. Temperature conditioning and surface treatments of grapefruit affect expression of chilling injury and gas diffusion. J. Amer. Soc. Hort. Sci. 118:490-496.

McKersie, B.D., Y. Chen, M. De Beus, S.R. Bowley, C. Bowler, D. Inze, K. D'Hallium, and J. Botterman. 1993. Superoxide dismutase enhances tolerances of freezing stress in transgenic alfalfa (Medicago sativa L.). Plant 
Physiol. 103:1155-1163.

Meir, S., S. Philosaph-Hadas, and N. Aharoni. 1992. Ethylene-increased accumulation of fluorescent lipid-peroxidation products detected during senescence of parsley by a newly developed method. J. Amer. Soc. Hort. Sci. 117:128-132.

O'Connor-Shaw, R.E., R. Roberts, A.L. Ford, and S.M. Nottingham. 1994. Shelf life of minimally processed honeydew, kiwifruit, papaya, pineapple and cantaloupe. J. Food Sci. 59:1202-1206,1215.

Paliyath, G. and J.E. Thompson. 1987. Calcium- and calmodulin-regulated breakdown of phospholipid by microsomal membranes from bean cotyledons. Plant Physiol. 83: 63-68.

Pauls, K.P. and J.E. Thompson. 1984. Evidence for the accumulation of peroxidized lipids in membranes of senescing cotyledons. Plant Physiol. 75:1152-1157.

Payton, P., R.D. Allen, N. Trolinder, and A.S. Holaday. 1997. Over-expression of chloroplast-targeted Mn superoxide dismutase in cotton (Gossypium hirsutum L. cv. Coker 312) does not alter the reduction of photosynthesis after short exposures to low temperature and high light intensity. Photosyn. Res. 52:233-244.

Pesis, E., R. Marinansky, G. Zauberman, and Y. Fuchs. 1994. Prestorage lowoxygen atmosphere treatment reduces chilling injury symptoms in 'Fuerte' avocado fruit. HortScience 29:1042-1046.

Pinhero, R.G., M.V. Rao, G. Paliyath, D.P. Murr, and R.A. Fletcher. 1997. Changes in activities of antioxidant enzymes and their relationship to genetic and paclobutrazol-induced chilling tolerance of maize seedlings. Plant Physiol. 114:695-704.

Pogson, B.J. and S.C. Morris. 1997. Consequences of cool storage of broccoli on physiological and biochemical changes and subsequent senescence at 20 degrees C. J. Amer. Soc. Hort. Sci. 122:553-558.

Polodorios, A.N. and J.G. Scandalios. 1997. Response of the maize catalases to light. Free Rad. Biol. Med. 23:497-504.

Prasad, T.K. 1996. Mechanisms of chilling-induced oxidative stress injury and tolerance in developing maize seedlings: Changes in antioxidant system, oxidation of proteins and lipids, and protease activities. Plant J. 10:10171026.

Prasad, T.K. 1997. Role of catalase in inducing chilling tolerance in preemergent maize seedlings. Plant Physiol. 114:1369-1376.

Purvis, A.C. 1997. Role of the alternative oxidase in limiting superoxide production by plant mitochondria. Physiol. Plant. 100:165-170.

Purvis, A.C. and R.L. Shewfelt. 1993. Does the alternative pathway ameliorate chilling injury in sensitive plant tissue? Physiol. Plant. 88:712-718.

Purvis, A.C., R.L. Shewfelt, and J.W. Gegogeine. 1995. Superoxide production by mitochondria isolated from green bell pepper fruit. Physiol. Plant. 94:743-749.

Rafi, M.M., R.S. Zemetra, and P.H. Berger. 1996. Jasmonic acid-methyl esterinduced protein profile modifications in wheat (Triticum aestivum L.). Acta Physiol. Plant. 18:53-58.

Raison, J.K. and G.R. Orr. 1990. Proposals for a better understanding of the molecular basis of chilling injury, p. 145-164. In: C.Y. Wang (ed.). Chilling injury of horticultural crops. CRC Press, Boca Raton, Fla.

Rao M.V., C.B. Watkins, S.K. Brown, and N.F. Weeden. 1998. Active oxygen species in 'White Angel' $x$ 'Rome Beauty' apple selections resistant and susceptible to superficial scald. J. Amer. Soc. Hort. Sci. 123:299-304.

Rogiers, S.Y., G.N.M. Kumar, and N.R. Knowles. 1998. Maturation and ripening of fruit of Amelanchier alnifolia Nutt. are accompanied by increasing oxidative stress. Ann. Bot. 81:203-211.

Roskruge, C.L. and M.T. Smith. 1997. Peroxidative changes associated with chilling injury in soybean seeds during imbibition. J. Plant Physiol. 151:620626.

Roxas, V.P., R.K. Smith, E.R. Allen, and R.D. Allen. 1997. Overexpression of glutathione $S$-transferase and glutathione peroxidase enhances the growth of transgenic tobacco seedlings during stress. Nature Biotech. 15:988-991.
Sabehat, A., S. Lurie, and D. Weiss. 1998. Isolation and characterization of a heat-induced gene, hcit2, encoding a novel $16.5 \mathrm{kDa}$ protein: Expression coincides with heat-induced tolerance to chilling stress. Plant Mol. Biol. 36:935-939.

Sabehat, A., D. Weiss, and S. Lurie. 1996. The correlation between heat-shock protein accumulation and persistence and chilling tolerance in tomato fruit. Plant Physiol. 110:531-537.

Shewfelt, R.L. 1992. Response of plant membranes to chilling and freezing, p. 192-219. In: Y.Y. Leshem (ed.). The plant membrane: A biophysical approach. Kluwer, Dordrecht, The Netherlands.

Shewfelt, R.L. and M.E. Erickson. 1991. Role of lipid peroxidation in the mechanism of membrane-associated disorders in edible plant tissue. Trends Food Sci. Technol. 6:152-154.

Shewfelt, R.L., M.E. Erickson, and K.H. McWatters. 1994. Peroxidation of isolated microsomal membranes from nongreen plant tissue. J. Plant Physiol. 143:670-674.

Shewfelt, R.L. and A.C. Purvis. 1995. Toward a comprehensive model for lipid peroxidation in plant tissue disorders. HortScience 30:213-218.

Silver, B.L. 1985. The physical chemistry of membranes: An introduction to the structure and dynamics of biological membranes. Solomon Press, New York.

Sung, J.M. 1996. Lipid peroxidation and peroxide-scavenging in soybeans during aging. Physiol. Plant. 97:85-89.

Sung, J.M. and C.C. Chiu. 1995. Lipid peroxidation and peroxide-scavenging enzymes of naturally aged soybean seed. Plant Sci. 110:45-52.

Tepperman, J.M. and P. Dunsmuir. 1990. Transformed plants with elevated levels of chloroplastic SOD are not more resistant to superoxide toxicity. Plant Mol. Biol. 14:501-511.

Tijskens L.M.M., E.C. Otma, and O. van Kooten. 1994. Photosystem II quantum yield as a measure of radical scavengers in chilling injury in cucumber fruits and bell peppers-A static and statistical model. Planta 194:478-486.

Walker, M.A. and B.D. McKersie. 1993. Role of the ascorbate-glutathione antioxidant system in chilling resistance of tomato. J. Plant Physiol. 141:234-239.

Wang, C.Y. 1995. Effect of temperature preconditioning on catalase, peroxidase, and superoxide dismutase in chilled zucchini squash. Postharvest Biol. Technol. 5:67-76.

Wang, C.Y. 1996. Temperature preconditioning affects ascorbate antioxidant system in chilled zucchini squash. Postharvest Biol. Technol. 8:29-36.

Wang, C.Y. and P. Sass. 1994. Reduction of chilling injury by methyl jasmonate. Acta Hort. 368:901-907.

Wang, J.K., T. Fujimoto, Y. Miazawa, Y. Endo, and K. Kitamura. 1990. Sensitivities of lipoxygenase-lacking soybean seeds to accelerated aging and their chemiluminescence levels. Phytochemistry 29:3739-3742.

Wismer, W.V., W.M. Worthing, R.Y. Yada, and A.G. Marangoni. 1998. Membrane lipid dynamics and lipid peroxidation in the early stages of lowtemperature sweetening in tubers of Solanum tuberosum. Physiol. Plant. 102:396-410.

Ye, B. and J. Gressel. 1994. Constitutive variation of ascorbate peroxidase activity during development parallels that of superoxide dismutase and glutathione reductase in paraquat-resistant conza. Plant Sci. 102:147151.

Zhang, C.L., P.H. Li, and C.C. Shin. 1994. GLK-8903 reduces membrane phospholipid degradation and alleviates chilling injury in Phaseolus vulgaris L. J. Amer. Soc. Hort. Sci. 119:307-312.

Zhang, J.X., S.P. Cui, J.M. Li, J.K. Wei, and M.B. Kirkham. 1995. Protoplasmic factors, antioxidant responses, and chilling resistance in maize. Plant Physiol. Biochem. 33:567-575.

Zhuang, H., D.F. Hildebrand, and M.M. Barth. 1995. Senescence of broccoli buds is related to changes in lipid peroxidation. J. Agr. Food Chem. 43:2585-2591. 